\title{
A Review on Cetylpyridinium Chloride
}

\author{
Nasila K ${ }^{1}$, Shijith K V ${ }^{2}$, Mohammed Shihab K K ${ }^{3}$, Ramya $C^{4}$ \\ ${ }^{1,3,4}$ M Pharm Student, College of Pharmaceutical Sciences, Government Medical College, Kannur. \\ ${ }^{2}$ Assistant Professor, College of Pharmaceutical Sciences, Government Medical College, Kannur.
}

Corresponding Author: Nasila K

\begin{abstract}
Cetylpyridinium chloride (CPC) is a quaternary ammonium surfactant having broad spectrum antimicrobial activity. The hexadecane chain of the CPC disorganizes lipid membrane and produces a complete rupture of the bacterial cell membrane. At low concentration of CPC, it leads to activation of intracellular latent ribonucleases of microbes to promote cell autolysis. At high concentration, CPC forms a vesicle-like structure in the bacterial cell surface and leads to leakage of cytoplasmic content. CPC can be estimated using several methods like HPLC, ion-pair extraction TLC, spectrophotometry, chemiluminescence, and spectrometry. It is a strong antimicrobial, anti plaque, deodorizer and bleeding control agent and is widely used in mouthwashes, tooth paste, sanitizers and disinfecting liquids.
\end{abstract}

Keywords- Cetylpyridinium chloride, antimicrobial agent, deodorizer, anti plaque agent.

\section{INTRODUCTION}

Cetylpyridinium Chloride (CPC) is an amphiphilic quaternary ammonium surfactant with $\mathrm{N}$ - hexadecyl pyridinium as cation and chloride ion as an anion (Figure 1). Due to the presence of a positive charge, it can easily bind to the negative cell membrane of microbes and destroy the cell integrity causing leakage of cellular components. This mechanism of action proves a broad-spectrum antimicrobial activity of CPC and is widely used as an antiseptic or disinfectant in different formulations like mouthwashes, lozenges, tablets, and also a cleaning solution for eatables.

\section{Chemical and physical properties}

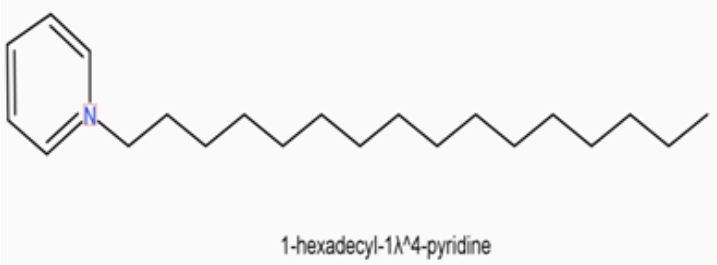

Figure 1: chemical structure of 1-hexadecylpyridin-1-ium chloride.

CPC is a chloride salt of cetylpyridinium ion. It has a molecular formula of $\mathrm{C}_{12} \mathrm{H}_{38} \mathrm{ClN}$ with a molecular weight of $340 \mathrm{~g} / \mathrm{mol}$. The IUPAC name is 1 hexadecylpyridin-1-ium chloride and is available as a white, non-hygroscopic, dry powder with a melting point of $80^{\circ} \mathrm{C}$. It has an extensive solubility characteristics in water and other organic solvents like alcohol and chloroform $(\log \mathrm{P}=1.71)$. CPC decomposes to produce toxic fumes of nitrogen oxides and hydrogen chloride. The $\mathrm{pH}$ of $1 \%$ aqueous solution of CPC is found to be neutral (6.0-7.0). Since it is a surfactant, it shows a surface tension value 43 dyne/cm ( $0.1 \%$ aqueous solution), 41 dyne/cm (1.0\% aqueous solution), 38 dyne/cm (10\% aqueous solution) for Cetylpyridinium chloride monohydrate at $25^{\circ} \mathrm{C}^{(1)}$

\section{Mechanism of action of Cetylpyridinium Chloride as an antimicrobial agent}

CPC is a highly effective antimicrobial agent and it is effective 
against Gram-positive, Gram-negative and even viruses. The cell wall of Gram-positive and Gram-negative bacteria is made up of lipoteichoic acid and lipopolysaccharides respectively along with phospholipid bilayer. All these elements contribute a negative charge to the bacterial membrane and this charge is stabilized by some positive counter ions like magnesium and calcium ions (Figure 2). The positive pyridine ion from CPC displaces these counter ions and produce interaction with the cell membrane (Figure 3\&4). Also, the hexadecane chain of the same disorganizes lipid membrane and produce a complete rupture of the bacterial cell membrane (Figure 5).

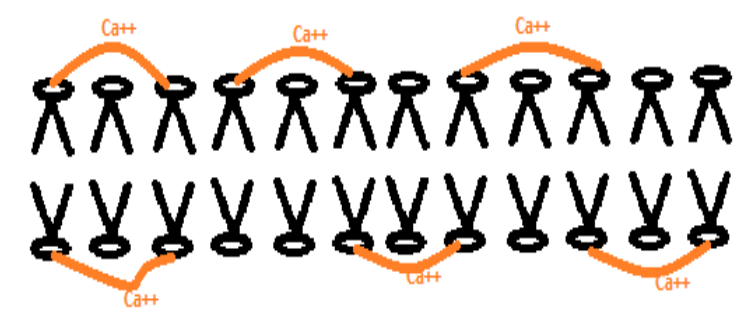

Figure 2: Stabilized biological membrane having negative phospholipids and positive counter ions

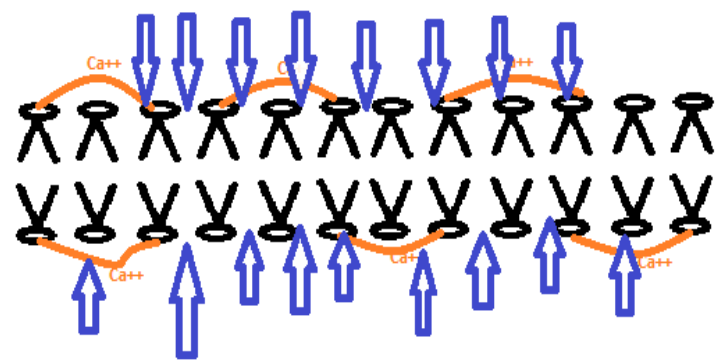

Figure 3: cationic surfactant approaches stabilized cell membrane.

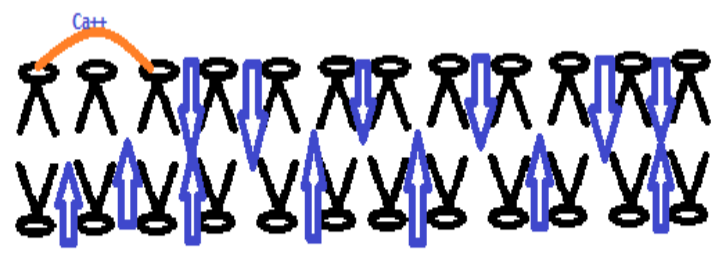

Figure 4: cationic surfactant replaces calcium ions from the stabilized cell membrane.

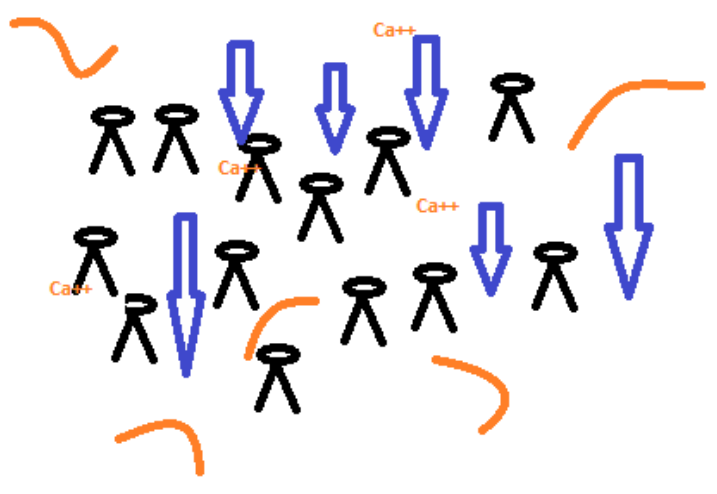

Figure 5: destruction of cell membrane.

The cell wall lysis mechanism in Gram-positive bacteria is quite understandable and convenient since it has a simple cell composition and comparatively less thickness with Gram-negative bacteria. The cell wall of Gram-negative bacteria is only permeable to molecules of weight less than 600 Da. Since CPC has a molecular weight of $339 \mathrm{Da}$, it is easily permeable and causes cell disruption in Gram-negative bacteria also.

At low concentration of $\mathrm{CPC}$, it leads to activation of intracellular latent ribonucleases of bacteria to promote leakage of potassium ions and pentose. These intracellular changes lose osmoregulation and homeostasis of the cell and finally autolysis. At high concentration, CPC forms a vesicle-like structure in the bacterial cell surface and leads to a series of consequences like membrane rupture, leakage of cytoplasmic content, protein and nucleic acid damage etc. Due to the surfactant property of CPC, it gets evenly distributed in the irregular surfaces to provide an extra contribution to the antimicrobial activity. ${ }^{(2)}$

\section{ESTIMATION OF CPC IN PHARMACEUTICALS AND COSMACEUTICALS}

CPC is widely used in pharmaceuticals and cosmaceuticals. It may causes some kinds of toxicity, eye irritation etc while taken in excess amount. Therefore its content estimation in pharmaceuticals and cosmaceuticals is important. CPC can 
be determined using several methods like HPLC, ion-pair extraction TLC, spectrophotometry, chemiluminescence, and spectrometry. $^{(3)}$

\subsection{Floatation Spectrophotometric Method:}

It is used for the quantitative determination of CPC in pharmaceuticals than cosmaceuticals. The principle behind this method of determination is the formation of ion associate with $\mathrm{OR}$ and then extraction CPC+_OR- ion pair to the interface between aqueous and n-hexane phase by methods like floatation. ${ }^{(4)}$

\subsection{Spectrophotometric Determination of Cetylpyridinium Chloride with Titan Yellow:}

It is a new spectrophotometric method used for the determination of CPC without extraction of ion pair. Here a colored compound is formed by reacting titan yellow and CPC (Figure 6). This compound can be directly estimated quantitatively to determine the concentration of CPC using UV Visible spectrophotometer in aqueous solution. ${ }^{(5)}$

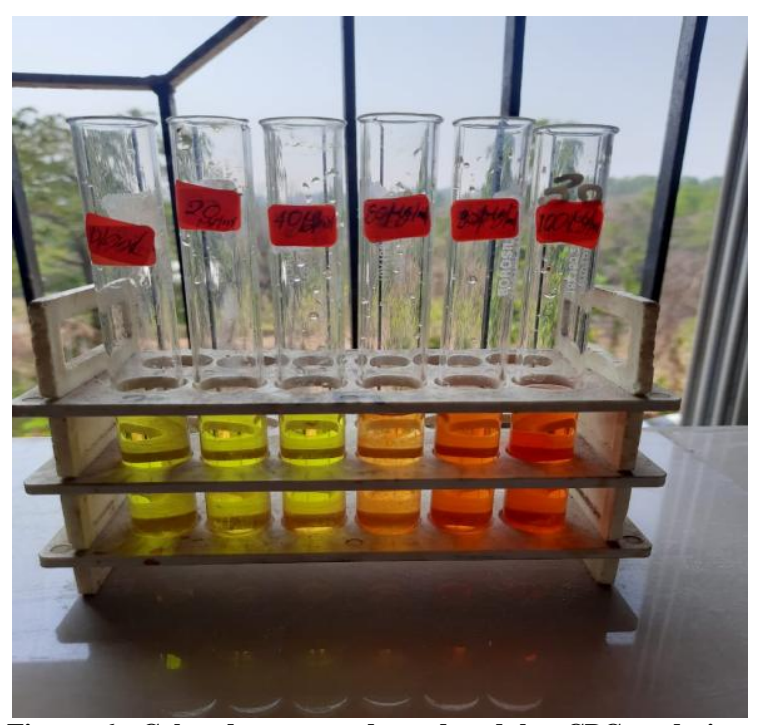

Figure 6: Colored compound produced by CPC and titan yellow

\subsection{High Performance Liquid \\ Chromatography (HPLC):}

It is also used for the quantitative determination of CPC. HPLC is considered as the most sensitive method for the determination of residual concentration of $\mathrm{CPC}$ on poultries or vegetables after surface cleaning with CPC. (6) A hydrophilic interaction chromatography column is introduced in HPLC to facilitate the simple, rapid, stable and accurate method. ${ }^{(7)}$

\section{PROPERTIES OF CPC}

\subsection{Antimicrobial Property}

$\mathrm{CPC}$ is a potent antimicrobial agent against Gram-positive and Gram-negative bacteria, enveloped viruses, fungi and algae. Its effective concentration against microbes is in a range of $0.05 \%$ to $0.1 \%$. Above this concentration, it becomes toxic to human beings and cannot be used as a therapeutic agent. Below this concentration, it is less effective as an antimicrobial agent. The best concentration at which rapid but short antimicrobial action provided is $0.07 \%$. Majority of over the counter antimicrobial products of $\mathrm{CPC}$ is available in this concentration. ${ }^{(8)}$

Due to this wide antimicrobial activity, it has been used as an important ingredient in mouth rinses to control the oral pathogens. As we know the oral cavity is highly prominent to infections with many Gram-positive negative bacteria. The biofilms formed by these bacteria are difficult to remove by using simple surfactant-containing normal kinds of toothpaste and mouthwashes. (9) So to disrupt and to prevent the further development of microbial biofilms, it is important to increase the usage of mouth rinses containing CPC. Since CPC offers antimicrobial action along with surfactant property, it is convenient and affordable as a complete solution for oral pathogens. ${ }^{(2)}$ On comparing with gold standard chlorhexidine, CPC can diffuse into the extracellular components of biofilms irrespective of the thickness to irreversibly bind with biofilms and prevents the formation of insoluble glucans. ${ }^{(10)}$ As we have already mentioned, CPC has a wide range of solubility and compatibility. These properties of CPC offer flexibility in the 
design of various dosage forms according to the need of patients and occasions. CPC has proven efficacy against oropharyngeal candidiasis and infections caused by herpes simplex viruses (HSV). HSV is a large enveloped virus, upon applying CPC on herpetic lesions caused by HSV produce dramatic changes as compared to acyclovir. Because acyclovir cannot offer a complete recovery from HSV infection, only reduces the duration of ulcers for one or few days. But CPC is efficient in treating the herpetic lesions by simple topical application. It is because of the ability of CPC to block the replication of HSV by interfering with the signaling pathway, $\mathrm{NF} \mathrm{Kb}$ for the expression of the viral gene. ${ }^{(11)}$

CPC is also used as an antimicrobial cleaning agent for eatables including poultries. As poultry washing agent it offers complete eradication of microbes including Salmonella typhimurium and e coli up to 2.5 logs. CPC prevents cross-contamination also. But the effective concentration range as a poultry washing antimicrobial is somewhat increased to the range of $0.5 \%$ to 1\%. Even though CPC is used as a disinfectant here, proper rinsing after applying the CPC is necessary to reduce the risk associated with CPC while consuming these eatables as food. Treatment with 0.5 $\% \mathrm{CPC}$ is somehow safe rather than using $1 \%$. That is upon treatment with $1 \% \mathrm{CPC}$, the residual level is excess for human consumption. Additionally, like other cleaning agents of eatables, it does not react with the meat components like proteins and fatty acids and also there is no change in color, odor and texture of eatables after applying CPC on surfaces. Therefore it is widely used in poultry washing purposes for beef trimmings before grinding. It remains active and keeps the poultries free from microbes during storage ${ }^{(11)} \mathrm{CPC}$ has been used in combination with acidified sodium chloride for reducing the microbial content other than salmonellae like E Coli, L. Monocytogenes and staphylococcus aureus. ${ }^{(12)}$ CPC can be applied as a spray solution to the poultries or the poultries can readily soak in CPC solution. Whatever be the treatment an effective rapid and spontaneous reduction of the count is observed for aerobic bacteria, coliform, salmonella and E Coli. CPC is an approved poultry washing agent in the US and EU (21 CFR 173.375: FDA 2003) and is marketed as Cecure by safe foods corporation in the US. ${ }^{(13)}$

\subsection{Antiplaque And Bleeding Control Effects Of CPC}

CPC has antiplaque activity in addition to antimicrobial action. ${ }^{(14)}$ This antiplaque activity is contributed by the cationic component of CPC. That is the cationic component can easily bind with negatively charged intraoral proteins that attribute plaque in the oral tissues. Upon the proliferation of these dental plaque causes chronic inflammatory and periodontal disease. ${ }^{(15)}$ Mechanical method to overcome the removal of dental plaque is tooth brushing. But it is difficult to execute in patients suffering from periodontal disease. So the use of mouthwashes along with tooth brushing promotes complete oral hygiene. Mouthwashes have the ability to penetrate intraoral tissues effectively. ${ }^{(16)}$ The widely used antiplaque agent is commonly available mouthwashes is chlorhexidine and is of the gold standard. ${ }^{(17)}$ But the long term use of chlorhexidine containing mouthwashes discolors the teeth, tongue, and parageusia and also causes irritation and hypersensitivity reactions in the oral mucosa. ${ }^{(18)} \mathrm{CPC}$ is a better and effective alternative for chlorhexidine. ${ }^{(19)}$ Since CPC is comparatively less effective in controlling dental plaque with chlorhexidine, it produces fewer side effects and therefore more convenient for long term use. CPC reduces the bacterial count that causing plaque and periodontal disease and eliminates the occurrence of gingivitis and halitosis. ${ }^{(20)}$ 


\subsection{DEODOURIZATION ABILITY OF CPC}

The foul smell of the oral cavity is also due to the accumulation and proliferation of some kinds of bacteria. The production of bad breath from the oral cavity is known as halitosis. This situation is embarrassing and leads to serious anxiety disorders if not treated properly. Microscopically tongue has an uneven surface and can easily trap the bacteria for a long time in the oral cavity. Upon sustained duration, they produce bad smell producing volatile sulfur compounds. CPC is known to reduce the concentration of volatile sulfur compounds by preventing the accumulation and proliferation of foul smell producing bacteria in the oral cavity. ${ }^{(21)}$

\section{PHARMACEUTICAL APPLICATIONS OF CPC}

\subsection{Mouthwashes}

CPC is widely used in over the counter mouthwashes alone or in combination with others. The antimicrobial, anti plaque, anti gingivitis, anti bleeding and deodorizing abilities of CPC is utilized in mouthwashes. ${ }^{(22)}$ The effective concentration range for CPC in mouthwash is $0.05 \%$ to $0.1 \%$. The commonly used concentration in market available CPC containing mouthwash is $0.07 \%$. Because according to many studies at this concentration, the highly accepted minimum inhibitory concentration is $0.07 \%$. there are many studies are conducted to detect the efficacy of CPC containing mouthwashes against the Covid 19 pandemic viruses and is proven that CPC can reduce the count of the virus by $99.9 \%$ along with zinc and stannous. ${ }^{(23) \text {, }}$ (24)

\subsection{Toothpaste}

In toothpaste, CPC provides multi actions, which are it can produce foam as a detergent while providing antimicrobial activity. Comparing with fluoridecontaining toothpaste, it can reduce plaque and gingivitis for a long duration up to 12 days with minimal side effects. The toothpaste formula normally contains an anionic surfactant and sweetener. While designing CPC containing mouthwashes It is important to consider the possible interaction of CPC with negatively charged surfactants. Since CPC is positively charges component, the main mechanism behind its antiplaque activity is to bind with negatively charged tooth surfaces. The possible interaction with anionic surfactant will lead to reduced antiplaque activity, thereby failed to meet the requirements of the toothpaste. (25)

\subsection{Buccal Tablets}

Mucoadhesive patches or tablets are designed to produce a complete cure from oral bacteria causing gingivitis and herpetic lesions by providing sustained and prolonged release of CPC for a long duration to make an intimate and effective contact of CPC with oral mucosa contaminated with pathogens. ${ }^{(26),(27)}$

\subsection{Hand Sanitizer}

The importance of hand sanitizer is increasing day by day. The development of alcohol or non-alcohol based sanitizer by incorporating CPC as an antimicrobial agent is beneficial to overcome the short term action of alcohol due to its rapid evaporation. As discussed earlier CPC has broad-spectrum antimicrobial activity and is efficient to prepare sanitizing liquids due to its wide solubility in water and organic solvents. ${ }^{(28)}$

\subsection{Disinfecting Liquids}

In this Covid scenario, the need for sanitizing the surfaces of daily utilities including table, floor, and chair is high. $\mathrm{CPC}$ can be used for these purposes because of its broad-spectrum antimicrobial activity and also the cheap and affordable price. Disinfectant property of CPC is observed in the concentration range 0.5 to $1 \%$. ${ }^{(24)}$

\subsection{Cleaning Agent for Eatables}

As we have discussed, CPC is approved antimicrobial agent for cleaning 
the surfaces of eatables like vegetables, fruits and poultries such as beef and chicken for long term storage without altering their texture, color and odor. The effective concentration range is $0.5 \%$ to $1 \%$. The residual $\mathrm{CPC}$ on the surfaces is to be considered while consuming the eatables. (29)

\subsection{CPC in Cosmaceuticals}

The deodorizing and anti perspirant activities of CPC opened a new window to cosmaceuticals and nowadays CPC is widely accepted in cosmaceuticals. By inhibiting the growth of bacteria that causes foul or bad odor in perspiration, CPC plays an important role in antiperspirants and deodorizers.

\section{CONCLUSION}

CPC is a quaternary ammonium surfactant having wide range properties extending to many pharmaceutical and cosmaceutical applications. The broad spectrum antimicrobial activity along with anti plaque and deodorizing ability can be utilized to produce mouth washes, tooth pastes, hand sanitizers, cleaning solution for eatables including meat and fruits. Its concentration can be estimated using several spectrophotometric and chromatographic techniques. CPC opens a new window as a surfactant in this pandemic scenario.

\section{Acknowledgement: None}

\section{Conflict of Interest: None}

\section{Source of Funding: None}

\section{REFERENCES}

1. PubChem. Cetylpyridinium chloride [Internet]. [cited 2021 Jan 3]. Available from:

https://pubchem.ncbi.nlm.nih.gov/compoun $\mathrm{d} / 31239$

2. Mao X, Auer DL, Buchalla W, Hiller K-A, Maisch T, Hellwig E, et al. Cetylpyridinium Chloride: Mechanism of Action, Antimicrobial Efficacy in Biofilms, and
Potential Risks of Resistance. Antimicrob Agents Chemother. 2020 22;64(8).

3. M. Carmen Prieto-Blanco, María Fernández-Amado, Purificación. Surfactants in Cosmetics: Regulatory Aspects and Analytical Methods. (Analysis of Cosmetic Products).

4. Parham H, Moradi NP and D. Development of a flotation-spectrophotometric method for determination of cetylpyridinium chloride in pharmaceutical products. Quím Nova. 2011;34(5):884-7.

5. Liu Y-H, Zhan H-W, Ma W-X. Spectrophotometric Determination of Cationic Surfactant with Titan Yellow. Asian J Chem. 2013;25(5):2736-8.

6. Abdelwahab NS, Ali NW, Abdelkawy M, Emam AA. Validated RP-HPLC and TLCDensitometric Methods for Analysis of Ternary Mixture of Cetylpyridinium Chloride, Chlorocresol and Lidocaine in Oral Antiseptic Formulation. J Chromatogr Sci. 2016 Mar 1;54(3):318-25.

7. Manikandan K, Lakshmi KS, Pai A. QbD approach in RP-HPLC method development for the assay of benzocaine and diclofenac in dosage forms. AIP Conf Proc. 2019 Jun 21;2112(1):020083.

8. Pahwa N, Kumar A, Gupta S. Short term clinical effectiveness of a $0.07 \%$ cetylpyridinium chloride mouth rinse in patients undergoing fixed orthodontic appliance treatment. Saudi Dent J. 2011 Jul;23(3):135-41.

9. Miranda SLF de, Damaceno JT, Faveri M, Figueiredo LC, Soares GMS, Feres M, et al. In Vitro Antimicrobial Effect of Cetylpyridinium Chloride on Complex Multispecies Subgingival Biofilm. Braz Dent J. 2020 Apr;31(2):103-8.

10. Sreenivasan PK, Haraszthy VI, Zambon JJ. Antimicrobial efficacy of $0.05 \%$ cetylpyridinium chloride mouthrinses. Lett Appl Microbiol. 2013 Jan;56(1):14-20.

11. Alvarez DM, Duarte LF, Corrales N, Smith PC, González PA. Cetylpyridinium chloride blocks herpes simplex virus replication in gingival fibroblasts. Antiviral Res. 2020; 179:104818.

12. Özdemir H, Koluman A, Yıldırım Y. Effects of acidified sodium chlorite, cetylpyridinium chloride and hot water on populations of Listeria monocytogenes and Staphylococcus aureus on beef. Lett Appl Microbiol. 2006;43(2):168-73. 
13. Saucedo-Alderete RO, Eifert JD, Boyer RR, Williams RC, Welbaum GE. Cetylpyridinium chloride direct spray treatments reduce Salmonella on cantaloupe rough surfaces. J Food Saf. 2018 Aug;38(4):e12471.

14. Amini P, Araujo MWB, Wu M-M, Charles CA, Sharma NC. Comparative antiplaque and antigingivitis efficacy of three antiseptic mouthrinses: a two week randomized clinical trial. Braz Oral Res. 2009 Sep;23(3):319-25.

15. Al-Ghananeem AM, Leung KP, Faraj J, DeLuca PP. Development of a Sustained Antiplaque and Antimicrobial Chewing Gum of a Decapeptide. AAPS PharmSciTech. 2017 Aug;18(6):2240-7.

16. Brookes ZLS, Bescos R, Belfield LA, Ali $\mathrm{K}$, Roberts A. Current uses of chlorhexidine for management of oral disease: a narrative review. J Dent. 2020 Dec;103:103497.

17. Balagopal S, Arjunkumar R. Chlorhexidine: The gold standard antiplaque agent. J Pharm Sci Res. 2013 Dec 1;5:27018.

18. James P, Worthington HV, Parnell C, Harding M, Lamont $\mathrm{T}$, Cheung $\mathrm{A}$, et al. Chlorhexidine mouthrinse as an adjunctive treatment for gingival health. Cochrane Database Syst Rev [Internet]. 2017 Mar 31 [cited 2021 Apr 17];2017(3). Available from:

https://www.ncbi.nlm.nih.gov/pmc/articles/ PMC6464488/

19. Retamal-Valdes B, Soares GM, Stewart B, Figueiredo LC, Faveri M, Miller S, et al. Effectiveness of a pre-procedural mouthwash in reducing bacteria in dental aerosols: randomized clinical trial. Braz Oral Res [Internet]. 2017 [cited 2021 Apr 17];31(0). Available from: http://www.scielo.br/scielo.php?script=sci_a rttext\&pid=S1806-

83242017000100221\&lng=en\&tlng=en

20. Lee J-E, Lee J-M, Lee Y, Park J-W, Suh J$\mathrm{Y}$, Um H-S, et al. The antiplaque and bleeding control effects of a cetylpyridinium chloride and tranexamic acid mouth rinse in patients with gingivitis. J Periodontal Implant Sci. 2017 Jun;47(3):134-42.

21. Capps CL. Virucidal activities of cetylpyridinium chloride [Internet]. US20090232748A1, 2009 [cited 2021 Apr 17]. Available from:
https://patents.google.com/patent/US200902 32748A1/en

22. Schaeffer LM, Szewczyk G, Nesta J, Vandeven M, Du-Thumm L, Williams MI, et al. In vitro antibacterial efficacy of cetylpyridinium chloride-containing mouthwashes. J Clin Dent. 2011;22(6):1836.

23. Pérez-Errázuriz S, Velasco-Ortega E, Jiménez-Guerra Á, Aguilera-Navarro E. Cetylpyridinium Chloride as a Tool Against COVID-19. Int J Odontostomatol. 2021 Mar;15(1):27-30.

24. Pramod K, Kotta S, Jijith US, Aravind A, Abu Tahir M, Manju CS, et al. Surfactantbased prophylaxis and therapy against COVID-19: A possibility. Med Hypotheses. 2020 Oct; 143:110081.

25. Sheen S, Eisenburger M, Addy M. Effect of toothpaste on the plaque inhibitory properties of a cetylpyridinium chloride mouth rinse. J Clin Periodontol. 2003 Mar;30(3):255-60.

26. Zhang D, Liu C-H, Zhang J, Cai D, Yang X, $\mathrm{Li} \mathrm{S}$, et al. [Effects of cetylpyridinium chloride buccal tablets on halitosis induced by oral conditions]. Nan Fang Yi Ke Da Xue Xue Bao. 2014 Aug;34(9):1386-9.

27. Akbari J, Saeedi M, Morteza-Semnani K, Kelidari H, Lashkari M. Formulation and Characterization of Cetylpyridinium Chloride Bioadhesive Tablets. Adv Pharm Bull. 2014 Dec;4(4):385-90.

28. Levison LT, Forshee CA, Gronewald KH. Antiseptic Liquid Formulation, A Method for Its Use, and A Method for Preparing the Formulation [Internet]. US20120034314A1, 2012 [cited 2021 Apr 17]. Available from: https://patents.google.com/patent/US201200 34314A1/en

29. Wang H, Li Y, Slavik MF. Efficacy of cetylpyridinium chloride in immersion treatment for reducing populations of pathogenic bacteria on fresh-cut vegetables. J Food Prot. 2001 Dec;64(12):2071-4.

How to cite this article: Nasila K, Shijith K V, Mohammed Shihab K K et.al. A review on cetylpyridinium chloride. International Journal of Research and Review. 2021; 8(4): 439-445. DOI: https://doi.org/10.52403/ijrr.20210453 